\title{
上海大金山岛不同植被类型下土壤动物群落多样性
}

\author{
靳亚丽 ${ }^{1}$ 李必成 ${ }^{1}$ 耿 龙 $^{2}$ 卜 云 ${ }^{*}$ \\ 1 (上海科技馆, 上海自然博物馆, 自然史研究中心, 上海 200041) \\ 2 (上海海洋管理事务中心, 上海 200050)
}

\begin{abstract}
摘要: 大金山岛属上海市金山三岛海洋生态保护区，岛上土壤未受到人为活动的污染。为了解不同自然植被类型 下土壤动物群落结构组成及其生态分布, 于2015年秋季在大金山岛竹林、乔木林和灌木林的南、北坡中分别进行 土壤动物采样。结果显示: 6 个样地共捕获土壤动物 12,769 只, 隶属于 28 个类群, 优势类群为蜱螨亚纲和弹尾纲, 分 别占总捕获量的70.15\%和19.27\%; 常见类群有原尾纲、半翅目、膜翅目和线蚓科, 占总捕获量的7.06\%。北坡和南 坡优势类群均为蜱螨亚纲(74.26\%、65.32\%)和弹尾纲(16.52\%、22.49\%), 但常见类群和稀有类群存在一定差异。 不同植被类型土壤动物的群落结构组成存在一定差异, 但无论是北坡还是南坡密度均为灌木林 > 乔木林 > 竹 林, 类群数变化为灌木林 > 竹林 > 乔木林。无论北坡还是南坡, 不同植被类型下土壤动物群落生态指数各不相 同, Shannon-Wiener多样性指数、Pielou均匀度指数和Simpson优势度指数均为灌木林 > 乔木林 > 竹林。大金山 岛灌木林中土壤动物群落多样性高于乔木林和竹林，很可能与灌木林中较为适宜的微环境有关。
\end{abstract}

关键词: 岛屿; 自然植被; 群落密度; 坡度

\section{Soil fauna community in different natural vegetation types of Dajinshan Island, Shanghai}

\author{
Yali Jin ${ }^{1}$, Bicheng $\mathrm{Li}^{1}$, Long Geng ${ }^{2}$, Yun $\mathrm{Bu}^{1 *}$ \\ 1 Natural History Research Center, Shanghai Natural History Museum, Shanghai Science \& Technology Museum, \\ Shanghai 200041 \\ 2 Shanghai Administration Center for Ocean Affairs, Shanghai 200050
}

\begin{abstract}
Dajinshan Island is part of Jinshan Three-Islands Marine Natural Reserve. Soil on the island has not been polluted by human activities and it is therefore an ideal place to study island ecosystem diversity. To understand the composition and ecological distribution of soil fauna communities in different natural forest vegetation types on Dajinshan Island, the soil fauna communities in three natural forests including bamboo forest, arboreal forest, and shrubbery were investigated during autumn 2015. Each forest included both north slope and south slope regions. A total of 12,769 individuals of soil fauna belonging to 28 groups were collected. The dominant groups were Acari and Collembola, accounting for $70.15 \%$ and $19.27 \%$, respectively. The common groups were Protura, Hemiptera, Hymenoptera and Enchytraediae, and they accounted for $7.06 \%$ of the total in terms of individual numbers. The dominant groups were Acari $(74.26 \%, 65.32 \%)$ and Collembola $(16.52 \%, 22.49 \%)$ in both north slope and south slope regions, but differed in common groups and rare groups. The soil fauna communities were different in the three natural forests. In both north and south slope region, the density of soil fauna followed the order of: shrubbery $>$ arboreal forest $>$ bamboo forest, but the number of groups of soil fauna followed the order of: shrubbery $>$ bamboo forest $>$ arboreal forest. Different ecological indexes of soil fauna communities in the three natural forests were different. Shannon-Wiener index, Pielou index, and Simpson index followed the following order: shrubbery $>$ arboreal forest $>$ bamboo forest in both north and south slope regions. The Shannon-Wiener index was significantly different in the three natural forests. The higher soil fauna diversity in shrubbery was probably induced by the
\end{abstract}

收稿日期: 2016-10-21; 接受日期: 2016-12-31

基金项目：上海海洋管理事务中心2015年大金山岛生态调查项目、上海市自然科学基金资助项目(17ZR1418700)、上海科技馆引进高层次人才科研启 动项目和上海科技馆种子课题

* 通讯作者 Author for correspondence. E-mail: buy@sstm.org.cn 
favorable microenvironment.

Key words: Island; natural vegetation; community density; slope

土壤动物是重要的分解者, 在森林生态系统的 物质循环和能量流动过程中有着不可替代的作用 (Wolters, 2001; Decaënsa et al, 2006)。近年来, 国内 外学者对于森林土壤动物开展了大量研究, 结果表 明, 人为干扰(Malmström et al, 2008; 陈小鸟等, 2009a; Čuchta et al, 2012)、海拔(Sadaka \& Ponge, 2003; 陈小鸟等, 2009b)、植被(廖崇惠等, 1997; 林 英华等, 2005)等对土壤动物群落的动态分布均产生 直接或间接的影响。土壤动物与地上植物群落之间 有着动态的相互作用(Wardle et al, 2004), 已有研究 表明, 地上植被的演替变化明显影响地下土壤动物 群落组成(易兰, 2005)。

岛屿生态系统具有特殊的地理位置和环境特 点, 其中自然植被的变化对地下土壤动物会有怎样 的影响, 目前尚未见文献报道。国外对于岛屿土壤 动物的研究多集中于系统分类(Sterzynska \& Bloger, 2004; Babenko, 2010; Greenslade \& Convey, 2011), 群落多样性的研究相对较少, 仅有Addison等(2003) 研究了加拿大温哥华岛沿海温带森林的跳虫群落 多样性; Hugo等(2006)研究了亚南极地区的爱德华 王子岛上的土壤小型节肢动物, 发现该岛与邻近的 Marion岛上土壤动物多样性有显著差异; Gudleifsson 和 Bjarnadottir (2008)对冰岛上不同草 地中的跳虫群落多样性进行了比较研究。

国内岛屿土壤动物多样性的研究十分匮乏, 黄 杰灵 ${ }^{\mathbb{1}}$ 对浙江千岛湖人工形成的 16 个面积不等的岛 屿土壤动物的研究表明, 土壤节肢动物类群数随岛 屿等级的增大显著增多; 刘扬等(2011)发现崇明岛 不同土地利用类型中的土壤动物存在明显差异, 苗 圃和公园中的多样性较高, 农田的多样性最低; 谢 桐音 ${ }^{2}$ 对山东滨州贝壳堤岛土壤动物和跳虫群落的 生态学研究发现, 无植被覆盖的近海区域土壤动物 表现出逆层分布的现象, 且土壤跳虫丰度随覆被植 物多样性的增加而显著增加。

大金山岛是上海市金山三岛海洋生态保护区

(1) 黄杰灵 (2012) 千岛湖片段化景观中土壤节肢动物多样性研究. 硕 士学位论文, 中国计量学院, 杭州.

(2) 谢桐音 (2010) 滨州贝壳堤岛土壤动物和跳虫群落生态学定量研究. 硕士学位论文, 山东师范大学, 济南.
中最大的岛屿, 其自然植被保护良好, 土壤尚未受 到人为污染(程芳等, 2013), 是开展岛屿生态系统自 然植被中土壤动物多样性研究的理想样地。本文通 过对大金山岛具有代表性的3种自然植被的土壤动 物群落组成进行研究, 以期为上海及邻近地区自然 林地生物多样性的保护以及土壤生态系统评价及 修复提供一定的科学依据。

\section{1 材料与方法}

\section{1 研究区域概况}

大金山岛(3041'42" N, 12124'25" E)地处上海 金山区附近的杭州湾中, 位于中亚热带北缘, 是金 山三岛海洋生态自然保护区的核心区。大金山岛距 金山嘴海岸约 $6.6 \mathrm{~km}$, 东西长约 $1 \mathrm{~km}$, 宽约 $0.3 \mathrm{~km}$, 最高处海拔 $105.3 \mathrm{~m}$, 年平均气温 $15.8^{\circ} \mathrm{C}$, 土壤为褐 色山地黄壤, 降水充沛, 四周被水域包围, 属海洋 性气候, 温和湿润, 四季分明。岛上植被生长茂盛, 是上海地区野生植物资源最丰富的地方, 由于受人 为干扰少，岛上植被进入自然的次生演替过程(李 必成，2014)。代表性植被类型有：以野桐属 (Mallotus)、青冈属(Cyclobalanopsis)、润楠属 (Machilus)、樟属(Cinnamomum)、朴属(Celtis)、花 椒属(Zanthoxylum)、黄檀属(Dalbergia)植物为主的 乔木林; 以卫矛属(Euonymus)、大青属(Clerodendrun)、算盘子属(Glochidion)、柃属(Eurya) 植物为 主的灌木林; 以毛竹属(Phyllostachys)植物为主的 竹林(杨永川等, 2002)。

\section{2 采样方法}

分别在竹林北(ZL-N)、竹林南(ZL-S)、乔木林 北 (QML-N)、乔木林南 (QML-S)、灌木林北 (GML-N)、灌木林南(GML-S)共设置6个样地(图1), 每个样地随机设置 5 个采样点。于 2015 年秋季, 采用 土壤定量采样器, 在每个样点采集 $15 \mathrm{~cm} \times 15 \mathrm{~cm} \times$ $15 \mathrm{~cm}$ 的土样带回实验室, 采用干漏斗法分离土壤 动物, 土壤动物收集在 $95 \%$ 的乙醇溶液中。分离所 得的土壤动物采用体视显微镜观察, 参考《中国土 壤动物检索图鉴》(尹文英, 1998)和《中国亚热带土 壤动物》(尹文英, 1992)进行分类鉴定, 并统计数量。 

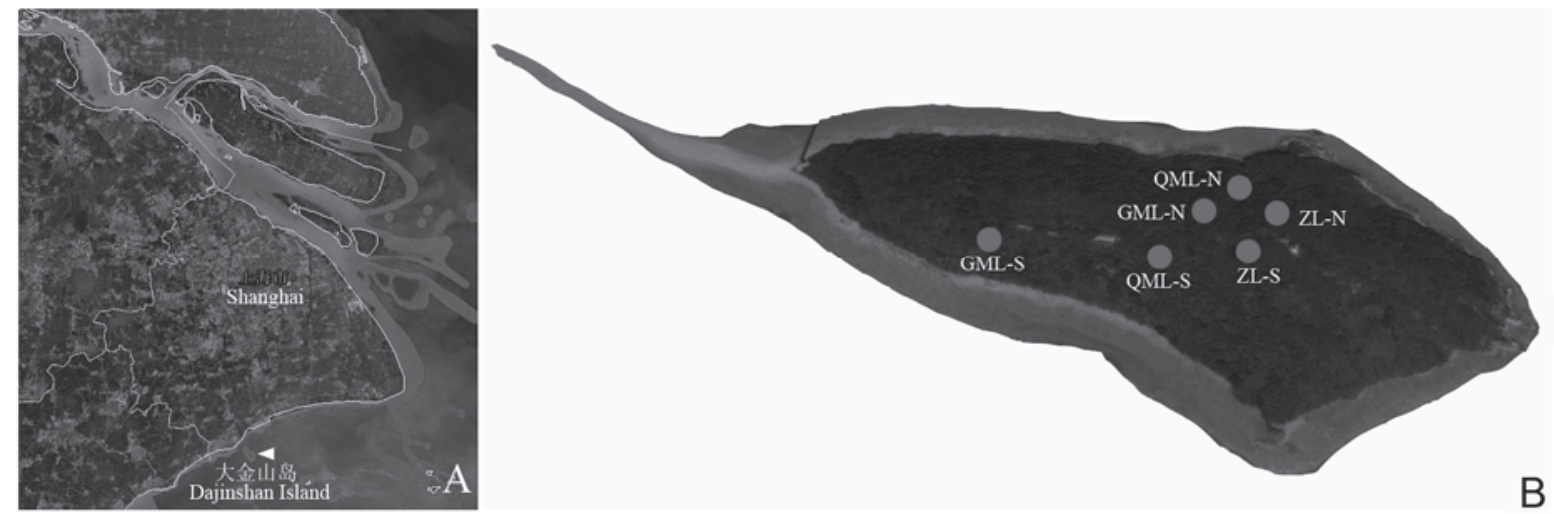

图1 大金山岛的地理位置及采样点设置。ZL: 竹林; QML: 乔木林; GML: 灌木林; N: 北坡; S: 南坡。

Fig. 1 The location of Dajinshan Island and soil fauna sampling sites. ZL, bamboo forest; QML, arboreal forest; GML, shrubbery; N, North slope; S, South slope.

\section{3 数据分析}

根据以下公式分别计算调落物中土壤动物群 落的多样性指数、均匀度指数、优势度指数和丰富 度指数(孙儒泳, 2001)。

(1) Shannon-Wiener 多样 性指数 $\left(H^{\prime}\right): H^{\prime}=$ $-\sum n_{\mathrm{i}} / N \ln \left(n_{\mathrm{i}} / N\right)$ 。

(2) Pielou均匀度指数 $(J s): J s=H^{\prime} / \ln S$ 。

(3) Simpson优势度指数 $(C): C=\sum P_{\mathrm{i}}^{2}$ 。

(4) Margalef丰富度指数 $(D): D=(S-1) / \ln N$ 。 式中, $n_{\mathrm{i}}$ 为第 $i$ 个类群的个体数; $N$ 为群落中所有类群 的总个体数; $S$ 为类群数; $P_{\mathrm{i}}=n_{\mathrm{i}} / N$ 。

我们定义密度 $>10 \%$ 的为优势类群; $1 \% \leq$ 密 度 $\% \leq 10 \%$ 的为常见类群; 密度 $<1 \%$ 的为稀有类 群。

采用Excel 2007进行图表绘制和计算, SPSS 19.0进行方差分析。

\section{2 结果}

\section{1 土壤动物群落组成及南北坡比较}

大金山岛自然植被调查共捕获土壤动物 12,769 只, 总密度为 31,528 只 $/ \mathrm{m}^{2}$, 隶属于 28 个类群。经统 计得出: 蜱螨亚纲、弹尾纲分别占总捕获量的 $70.15 \%$ 和 $19.27 \%$, 为优势类群; 原尾纲、半翅目、 膜翅目和线蚂科为常见类群, 合计占总捕获量的 $7.06 \%$; 双尾纲、直翅目等 21 个类群为稀有类群, 合 计占总捕获量的 $3.52 \%$ 。

北坡共捕获土壤动物26类6,901只, 占54.05\%, 南坡共捕获24类5,868只, 占45.96\%。北坡和南坡优
势类群均为蜱螨亚纲 (74.26\%、65.32\%)和弹尾纲 (16.52\%、22.49\%), 但常见类群和稀有类群存在一 定差异(表1)。北坡的常见类群为原尾纲和线蚓科, 占北坡总数的 $4.39 \%$, 南坡的常见类群为半翅目、双 翅目幼虫和膜翅目, 占南坡总数的 $8.27 \%$ 。稀有类群 中直翅目和缨翅目只在南坡出现，啮目、蜈蚣目、 后孔寡毛目和腹足纲只在北坡出现。

\section{2 各植被类型土壤动物密度比较}

不同植被类型中土壤动物密度和群落组成不 同(表2), 无论是北坡还是南坡密度均为灌木林 > 乔木林 > 竹林, 但各样地间密度和类群差异不显 著 $(P>0.05)$; 竹林和乔木林优势类群都包括蜱螨亚 纲 $(60.65 \% 、 63.41 \%)$ 和弹尾纲 $(28.41 \% 、 23.53 \%)$, 灌 木林优势类群只有蜱螨亚纲(81.95\%); 竹林和乔木 林的常见类群也相差不大, 都有原尾纲 $(2.79 \%$ 、 $1.84 \%)$ 、双翅目幼虫 $(1.21 \% 、 1.34 \%)$ 和膜翅目 (1.18\%、1.60\%)等，但灌木林常见类群与竹林、乔 木林不同，多了弹尾纲(9.93\%)、半翅目 $(2.57 \%)$ 等; 稀有类群组成也存在一定差异, 直翅目只在乔木林 出现, 等翅目、啮目、双翅目成虫和腹足纲只在灌 木林出现, 蜈蚣目只在竹林出现。三种植被类型下 土壤动物类群数为灌木林 > 竹林 > 乔木林。

\section{3 土壤动物群落多样性比较}

大金山岛不同植被类型下土壤动物群落各多 样性指数不同(图2)。无论北坡还是南坡, ShannonWiener多样性指数、Pielou均匀度指数和Simpson优 势度指数都是灌木林最高, 乔木林次之, 竹林最低, 且在竹林和乔木林两个类型中都是北坡高于南坡, 
表1 大金山岛南坡和北坡土壤动物群落组成和密度 $\left(\right.$ ind. $\left./ \mathrm{m}^{2}\right)$

Table 1 Soil fauna communities and densities (ind. $/ \mathrm{m}^{2}$ ) of south slope and north slope of Dajinshan Island

\begin{tabular}{|c|c|c|c|c|c|c|}
\hline \multirow{2}{*}{$\begin{array}{l}\text { 类群 } \\
\text { Group }\end{array}$} & \multicolumn{3}{|c|}{ 北坡 North slope } & \multicolumn{3}{|c|}{ 南坡 South slope } \\
\hline & $\begin{array}{l}\text { 个体数 } \\
\text { Individuals }\end{array}$ & $\begin{array}{l}\text { 密度 } \\
\text { Density (\%) }\end{array}$ & $\begin{array}{l}\text { 优势度 } \\
\text { Dominance }\end{array}$ & $\begin{array}{l}\text { 个体数 } \\
\text { Individuals }\end{array}$ & $\begin{array}{l}\text { 密度 } \\
\text { Density (\%) }\end{array}$ & $\begin{array}{l}\text { 优势度 } \\
\text { Dominance }\end{array}$ \\
\hline 蜱螨亚纲 Acari & 5,125 & $25,309(74.26)$ & +++ & 3,833 & $18,928(65.32)$ & +++ \\
\hline 弹尾纲 Collembola & 1,140 & $5,630(16.52)$ & +++ & 1,320 & 6,519 (22.49) & +++ \\
\hline 线虫纲 Nematoda & 62 & $306(0.90)$ & + & 198 & 978 (3.37) & ++ \\
\hline 原尾纲 Protura & 147 & $726(2.13)$ & ++ & 42 & $207(0.72)$ & + \\
\hline 线蚓科 Enchytraediae & 156 & $770(2.26)$ & ++ & 28 & $138(0.48)$ & + \\
\hline 半翅目 Hemiptera & 4 & $20(0.06)$ & + & 132 & $652(2.25)$ & ++ \\
\hline 膜翅目 Hymenoptera & 55 & $272(0.80)$ & + & 78 & $385(1.33)$ & ++ \\
\hline 双翅目幼虫 Diptera larvae & 48 & $237(0.70)$ & + & 77 & $380(1.31)$ & ++ \\
\hline 综合纲 Symphyla & 28 & $138(0.41)$ & + & 24 & $119(0.41)$ & + \\
\hline 等足目 Isopoda & 15 & $74(0.22)$ & + & 36 & $178(0.61)$ & + \\
\hline 少足纲 Pauropoda & 27 & $133(0.39)$ & + & 17 & $84(0.29)$ & + \\
\hline 倍足纲 Diplopoda & 25 & $123(0.36)$ & + & 16 & $79(0.27)$ & + \\
\hline 双尾纲 Diplura & 17 & $84(0.25)$ & + & 15 & $74(0.26)$ & + \\
\hline 鞘翅目成虫 Coleoptera adult & 10 & $49(0.14)$ & + & 11 & $54(0.19)$ & + \\
\hline 鞘翅目幼虫 Coleoptera larvae & 10 & $49(0.14)$ & + & 7 & $35(0.12)$ & + \\
\hline 拟蝎目 Pseudoscorpionida & 3 & $15(0.14)$ & + & 10 & $49(0.17)$ & + \\
\hline 石蜈蚣目 Lithobiomorpha & 7 & $35(0.10)$ & + & 5 & $25(0.09)$ & + \\
\hline 蜘蛛目 Araneae & 6 & $30(0.09)$ & + & 4 & $20(0.07)$ & + \\
\hline 缨翅目 Thysanoptera & 0 & 0 & & 6 & $30(0.10)$ & + \\
\hline 鳞翅目幼虫 Lepodoptera larvae & 5 & $25(0.07)$ & + & 1 & $5(0.02)$ & + \\
\hline 等翅目 Isoptera & 1 & $5(0.01)$ & + & 4 & $20(0.07)$ & + \\
\hline 地蜈蚣目 Geophilomorpha & 2 & $10(0.03)$ & + & 2 & $10(0.03)$ & + \\
\hline 后孔寡毛目 Oligochaetaopisthopora & 4 & $20(0.06)$ & + & 0 & 0 & \\
\hline 双翅目成虫 Diptera adult & 1 & $5(0.01)$ & + & 1 & $5(0.02)$ & + \\
\hline 直翅目 Orthptera & 0 & 0 & & 1 & $5(0.02)$ & + \\
\hline 啮目 Psocoptera & 1 & $5(0.01)$ & + & 0 & 0 & \\
\hline 蜈蚣目 Scolopendromorpha & 1 & $5(0.01)$ & + & 0 & 0 & \\
\hline 腹足纲 Gastropoda & 1 & $5(0.01)$ & + & 0 & 0 & \\
\hline 总数 Total & 6,901 & 34,079 & & 5,868 & 28,978 & \\
\hline
\end{tabular}

+++ 优势类群; ++ 常见类群; + 稀有类群。

+++ Dominant groups; ++ Common groups; + Rare groups.

灌木林只有Simpson优势度指数表现为北坡高于南 坡。对南坡各样地Shannon-Wiener多样性指数进行 比较发现：灌木林南坡与竹林南坡、乔木林南坡之 间存在显著差异 $(F=2.56, P<0.05)$ 。对各样地 Pielou均匀度指数进行方差分析发现：灌木林南坡 显著高于其他样地, 灌木林北坡显著高于竹林南和 乔木林南坡 $(F=3.08, P<0.05)$ 。灌木林不论南北坡 Simpson优势度都显著高于其他样地 $(F=8.13, P<$ 0.05)。竹林北坡与竹林南坡Margalef丰富度存在显
著差异 $(F=1.69, P<0.05)$ 。

\section{3 讨论}

\section{1 土壤动物群落组成与密度}

除温湿度外, 人为干扰是影响土壤动物群落结 构的主要因素(武海涛等, 2006), 大金山岛为自然演 替植被, 受人为干扰程度低, 土壤动物总密度明显 比上海市森林中土壤动物密度高(王强等, 2012; 靳 士科等, 2016), 类群数量多于上海城市绿地中土壤 
表2 大金山岛各植被类型中土壤动物群落组成和密度 $\left(\mathrm{ind} . / \mathrm{m}^{2}\right)$

Table 2 Soil fauna communities and densities (ind. $/ \mathrm{m}^{2}$ ) under different vegetation types on Dajinshan Island

\begin{tabular}{|c|c|c|c|c|c|c|c|c|c|}
\hline \multirow{2}{*}{$\begin{array}{l}\text { 类群 } \\
\text { Group }\end{array}$} & \multicolumn{3}{|c|}{ 竹林 Bamboo forest } & \multicolumn{3}{|c|}{ 乔木林 Arboreal forest } & \multicolumn{3}{|c|}{ 灌木林 Shrubbery } \\
\hline & $\begin{array}{l}\text { 个体数 } \\
\text { Indivi- } \\
\text { duals }\end{array}$ & $\begin{array}{l}\text { 密度 } \\
\text { Density (\%) }\end{array}$ & $\begin{array}{l}\text { 优势度 } \\
\text { Domin- } \\
\text { ance }\end{array}$ & $\begin{array}{l}\text { 个体数 } \\
\text { Indi- } \\
\text { viduals }\end{array}$ & $\begin{array}{l}\text { 密度 } \\
\text { Density (\%) }\end{array}$ & $\begin{array}{l}\text { 优势度 } \\
\text { Domin- } \\
\text { ance }\end{array}$ & $\begin{array}{l}\text { 个体数 } \\
\text { Indi- } \\
\text { viduals }\end{array}$ & $\begin{array}{l}\text { 密度 } \\
\text { Density (\%) }\end{array}$ & $\begin{array}{l}\text { 优势度 } \\
\text { Domin- } \\
\text { ance }\end{array}$ \\
\hline 蜱螨亚纲 Acari & 1,851 & $13,711(60.65)$ & +++ & 2,929 & $21,696(63.41)$ & +++ & 4,178 & 30,948 (81.95) & +++ \\
\hline 弹尾纲 Collembola & 867 & 6,422 (28.41) & +++ & 1,087 & 8,052 (23.53) & +++ & 506 & 3,748 (9.93) & ++ \\
\hline 线虫纲 Nematoda & 33 & $244(1.08)$ & ++ & 169 & $1,252(3.66)$ & ++ & 58 & $430(1.14)$ & ++ \\
\hline 原尾纲 Protura & 85 & $630(2.79)$ & ++ & 85 & $630(1.84)$ & ++ & 19 & $141(0.37)$ & + \\
\hline 线蚓科 Enchytraediae & 12 & $89(0.39)$ & + & 100 & $741(2.16)$ & ++ & 72 & $533(1.41)$ & ++ \\
\hline 半翅目 Hemiptera & 3 & $22(0.10)$ & + & 2 & $15(0.04)$ & + & 131 & $970(2.57)$ & ++ \\
\hline 膜翅目 Hymenoptera & 36 & 267 (1.18) & ++ & 74 & $548(1.60)$ & ++ & 23 & $170(0.45)$ & + \\
\hline 双翅目幼虫 Diptera larvae & 37 & $274(1.21)$ & ++ & 62 & $459(1.34)$ & ++ & 26 & $193(0.51)$ & + \\
\hline 综合纲 Symphyla & 24 & $178(0.79)$ & + & 15 & $111(0.32)$ & + & 13 & $96(0.26)$ & + \\
\hline 等足目 Isopoda & 15 & $111(0.49)$ & + & 20 & $148(0.43)$ & + & 16 & $119(0.31)$ & + \\
\hline 少足纲 Pauropoda & 33 & $244(1.08)$ & ++ & 5 & $37(0.11)$ & + & 6 & $44(0.12)$ & + \\
\hline 倍足纲 Diplopoda & 18 & $133(0.59)$ & + & 15 & $111(0.32)$ & + & 8 & $59(0.16)$ & + \\
\hline 双尾纲 Diplura & 2 & $15(0.07)$ & + & 23 & $170(0.50)$ & + & 7 & $52(0.14)$ & + \\
\hline 鞘翅目成虫 Coleoptera adult & 10 & $74(0.33)$ & + & 4 & $30(0.09)$ & + & 7 & $52(0.14)$ & + \\
\hline 鞘翅目幼虫 Coleoptera larvae & 7 & $52(0.23)$ & + & 6 & $44(0.13)$ & + & 4 & $30(0.08)$ & + \\
\hline 拟蝎目 Pseudoscorpionida & 1 & $7(0.03)$ & + & 11 & $81(0.24)$ & + & 1 & $7(0.02)$ & + \\
\hline 石蜈蚣目 Lithobiomorpha & 7 & $52(0.23)$ & + & 4 & $30(0.09)$ & + & 1 & $7(0.02)$ & + \\
\hline 蜘蛛目 Araneae & 1 & $7(0.03)$ & + & 4 & $30(0.09)$ & + & 5 & $37(0.10)$ & + \\
\hline 缨翅目 Thysanoptera & 2 & $15(0.07)$ & + & 2 & $15(0.04)$ & + & 2 & $15(0.04)$ & + \\
\hline $\begin{array}{l}\text { 鳞翅目幼虫 Lepodoptera lar- } \\
\text { vae }\end{array}$ & 2 & $15(0.07)$ & + & 0 & 0 & & 4 & $30(0.08)$ & + \\
\hline 等翅目 Isoptera & 0 & 0 & & 0 & 0 & & 5 & $37(0.10)$ & + \\
\hline 地蜈蚣目 Geophilomorpha & 1 & $7(0.03)$ & + & 1 & $7(0.02)$ & + & 2 & $15(0.04)$ & + \\
\hline $\begin{array}{l}\text { 后孔寡毛目 Oligochaetaopis- } \\
\text { thopora }\end{array}$ & 4 & $30(0.13)$ & + & 0 & 0 & & 0 & 0 & \\
\hline 双翅目成虫 Diptera adult & 0 & 0 & & 0 & 0 & & 2 & $15(0.04)$ & + \\
\hline 直翅目 Orthptera & 0 & 0 & & 1 & $7(0.02)$ & + & 0 & 0 & \\
\hline 啮目 Psocoptera & 0 & 0 & & 0 & 0 & & 1 & $7(0.02)$ & + \\
\hline 蜈蚣目 Scolopendromorpha & 1 & $7(0.13)$ & + & 0 & 0 & & 0 & 0 & \\
\hline 腹足纲 Gastropoda & 0 & 0 & & 0 & 0 & & 1 & $7(0.02)$ & \\
\hline 合计 Total & 3,052 & $22,607(100)$ & & 4,619 & $34,215(100)$ & & 5,098 & $37,763(100)$ & \\
\hline
\end{tabular}

+++ 优势类群; ++ 常见类群; + 稀有类群。

+++ Dominant groups; ++ Common groups; + Rare groups.

动物的类群数(高艳等, 2007)。

植物群落结构差异能够对土壤动物群落组成 产生影响(Kardol et al, 2010; 李伟等, 2015)。Gladys 等(2007)认为优势植物的调落物与土壤动物群落组 成具有一定的相关性, 丰富的植物群落结构增加了 地下土壤的异质性, 进一步影响土壤动物的群落组 成。本研究也发现不同植被类型中土壤动物密度、 类群数均存在一定程度差异, 且明显表现为植物群 落组成越简单的竹林土壤动物密度相对较低, 其次
分别为乔木林和灌木林。

此外, 不同林地调落物层各自特殊的组成成分 差异以及营养物质或次生物质间各自的相互作用, 为土层中土壤动物提供了不同的食物源和栖息小 环境, 这也是导致各林地间土壤动物组成差异的主 要原因之一(易兰等, 2005; 靳亚丽等, 2011)。

\section{2 各林地土壤动物多样性}

森林的次生演替对土壤动物群落结构产生影 响，大金山岛三种林型由于自然的次生演替形成 

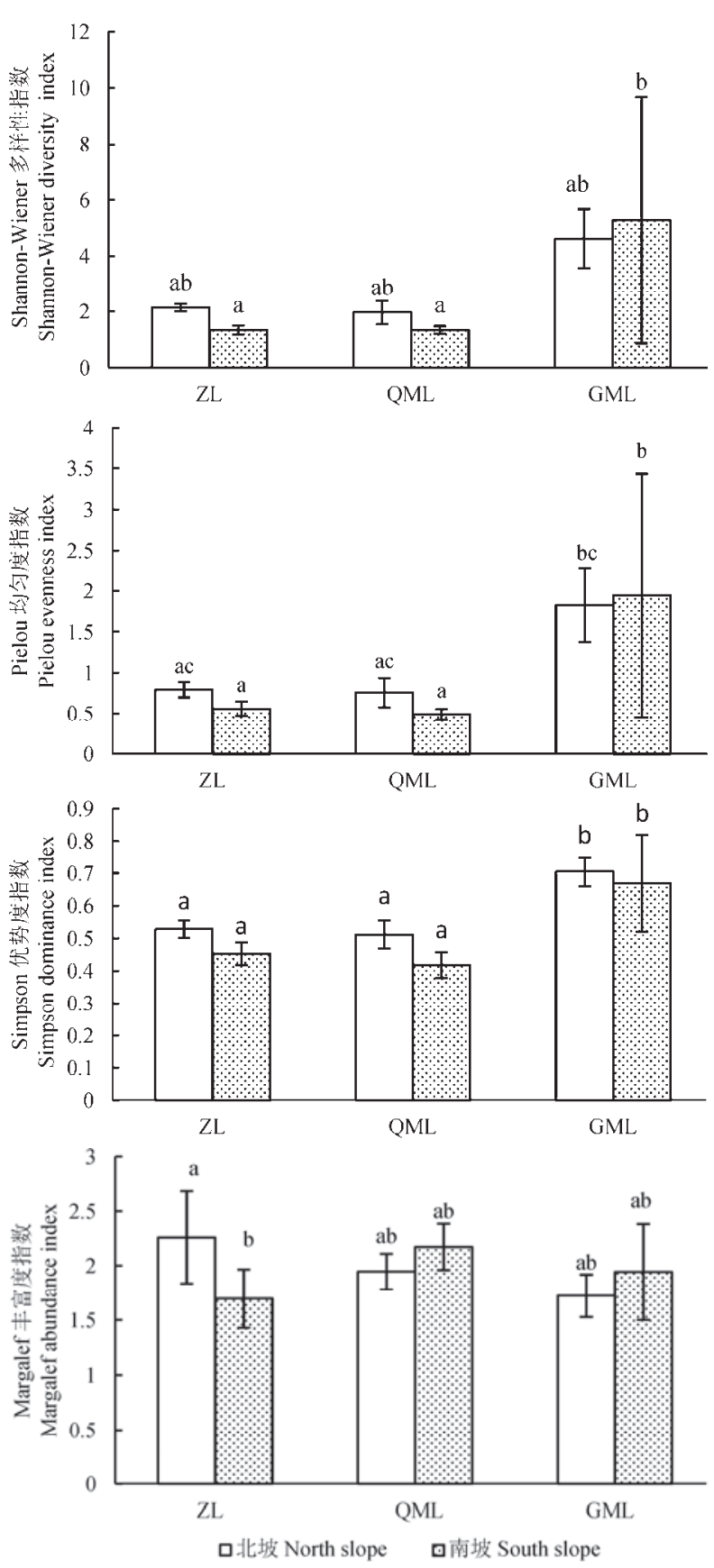

图2 大金山岛不同植被类型下土壤动物群落生态指数(平 均值 \pm 标准差)。字母不同表示差异显著 $(P=0.05)$ ＺLL: 竹 林; QML: 乔木林; GML: 灌木林。

Fig. 2 Ecological indices of soil fauna communities of different vegetation types in Dajinshan Island (Mean \pm SD). Different letters show the significant difference at $P=0.05$ level. ZL, bamboo forest; QML, arboreal forest; GML, shrubbery.

(达良俊等, 2004), 演替过程中植物群落的更替也是 导致土壤动物多样性差异的原因之一(易兰, 2005)。 本研究发现竹林土壤动物多样性均低于乔木林和
灌木林，苏永春等(2004)的研究结果也表明竹林土 壤动物丰度低, 竹林单一的植物群落可能是导致这 一结果的主要原因。北坡接受阳光照射较南坡少, 土壤湿度相对较高, 因而除灌木林外其他林型土壤 动物群落的Shannon-Wiener多样性指数、Pielou均匀 度指数和Simpson优势度指数都表现为北坡高于南 坡。灌木林相对于乔木林更接近地被层, 受外界环 境干扰较小, 容易在下层形成温暖潮湿的小气候而 更利于土壤动物的聚集, 因此灌木林土壤动物多样 性指数最高, 均匀度指数和优势度指数也显著高于 竹林和乔木林(图2)。而灌木林南坡相对位置较低, 靠近海域, 受海洋性气候影响而形成的土壤异质性 可能是导致该样地均匀度显著高于其他样地的原 因。

此外，本研究中竹林、乔木林和灌木林的位置 不同，难以避免空间异质性造成的影响，且南北坡 的差异是基于 3 种不同林型得出的结论，而不同林 地类型本身也存在差异，因此本研究只能说明该岛 屿土壤动物群落多样性的整体状况, 对于各林型和 坡向造成的土壤动物群落差异还有待进一步研究 和探讨。

致谢：本项目实施过程中受到上海市海洋局、上海 市金山区海洋海塘管理所等单位的大力支持，同时 感谢杨斯琦、杨刚、高如峰、王万胜、杜运才、巢 移等同志对本项目野外采样等工作的倾力协助。

\section{参考文献}

Addison JA, Trofymow JA, Marshall VG (2003) Abundance, species diversity, and community structure of Collembola in successional coastal temperate forests on Vancouver Island, Canada. Applied Soil Ecology, 24, 233-246.

Babenko AB (2010) The springtail (Hexapoda, Collembola) fauna of Wrangel Island. Entomological Review, 90, 571-584.

Chen XN, You WH, Wang XY, Yi L (2009a) Community traits of soil animal under different ground cover treatments in evergreen broad-leaved forest. Biodiversity Science, 17, 160-167. (in Chinese with English abstract) [陈小鸟, 由文 辉, 王向阳, 易兰 (2009a) 常绿阔叶林不同砍伐处理下 土壤动物的群落特征. 生物多样性, 17, 160-167.]

Chen XN, You WH, Yi L (2009b) Community structure of soil fauna along an altitudinal gradient in Taibai Mountain of Tiantong Region, Zhejiang Province. Chinese Journal of Ecology, 28, 270-276. (in Chinese with English abstract) [陈小鸟, 由文辉, 易兰 (2009b) 浙江天童太白山不同海 拔土壤动物的群落结构. 生态学杂志, 28, 270-276.] 
Cheng F, Cheng JP, Sang HC, Yu JL, Xi L, Pi SS (2013) Assessment and correlation analysis of heavy metals pollution in soil of Dajinshan Island. Environmental Science, 34, 1062-1066. (in Chinese with English abstract) [程芳, 程金 平, 桑恒春, 于金莲, 席否, 皮帅帅 (2013) 大金山岛土 壤重金属污染评价及相关性分析. 环境科学, 34, 1062-1066.]

Čuchta P, Miklisová D, Kováč L (2012) A three-year study of soil Collembola communities in spruce forest stands of the High Tatra Mts (Slovakia) after a catastrophic windthrow event. European Journal of Soil Biology, 50, 151-158.

Da LJ, Yang YC, Chen YP (2004) The diversity of plant community on Dajinshan Island, Shanghai. Journal of Chinese Urban Forestry, 2(3), 22-25. (in Chinese with English abstract) [达良俊, 杨永川, 陈燕萍 (2004) 上海大金山岛的 自然植物群落多样性. 城镇绿化, 2(3), 22-25.]

Decaënsa T, Jiménezb JJ, Gioiac C, Measeyb GJ, Lavelleb P (2006) The values of soil animals for conservation biology. European Journal of Soil Biology, 42, 23-38.

Gao Y, Bu Y, Luan YX, Yang YM, Ke X (2007) Community composition and diversity of soil fauna in the land use of city planning: a case study in Shanghai World Exposition Site. Biodiversity Science, 15, 207-214. (in Chinese with English abstract) [高艳, 卜云, 奕云霞, 杨毅明, 柯欣 (2007) 城市新规划地土壤动物群落组成和多样性: 以上 海市世博会会址为例. 生物多样性, 15, 207-214.]

Gladys LM, Daniel I, France BR, Patrick L (2007) Soil fauna abundance and diversity in a secondary semi-evergreen forest in Guadeloupe (Lesser Antilles): influence of soil type and dominant tree species. Biology and Fertility of Soils, 44, 269-276.

Greenslade P, Convey P (2011) Exotic Collembola on subantarctic islands: pathways, origins and biology. Biological Invasions, 14, 405-417.

Gudleifsson BE, Bjarnadottir B (2008) Springtail (Collembola) populations in hayfields and pastures in northern Iceland. Icelandic Agricultural Sciences, 21, 49-59.

Hugo EA, Chown SL, McGeoch MA (2006) The microarthropods of sub-Antarctic Prince Edward Island: a quantitative assessment. Polar Biology, 30, 109-119.

Jin SK, Wang JJ, Zhu S, Zhang Q, Li X, Zheng WJ, You WH (2016) Soil meso- and micro-fauna community structures in different urban forest types in Shanghai, China. Chinese Journal of Applied Ecology, 27, 2363-2371. (in Chinese with English abstract) [靳士科, 王娟娟, 朱莎, 张琪, 黎 翔, 郑文静, 由文辉 (2016) 上海市不同类型城市森林中 小型土壤动物群落结构特征. 应用生态学报, 27 , 2363-2371.]

Jin YL, You WH, Yi L, Wang XY, Wang Q (2011) Ecological distribution of collembola in the litter of Tiantong forest ecosystems, Zhejiang. Ecology and Environmental Sciences, 20, 241-247. (in Chinese with English abstract) [靳亚丽, 由文辉, 易兰, 王向阳, 王强 (2011) 天童森林生态系统 调落物层跳虫群落的生态学研究. 生态环境学报, 20,
241-247.]

Kardol P, Cregger MA, Campany CE, Classen AT (2010) Soil ecosystem functioning under climate change: plant species and community effects. Ecology, 91, 767-781.

Li BC (2014) Scientific Research Report of Dajinshan Island, Shanghai. Shanghai Science and Technology Education Publishing House, Shanghai. (in Chinese) [李必成 (2014) 大金山岛科学考察报告. 上海科技教育出版社, 上海.]

Li W, Cui LJ, Zhao XS, Zhang MY, Gao CJ, Zhang Y, Wang YF (2015) Community structure and diversity of soil animals in the Lake Taihu ladeshore wetland. Acta Ecologica Sinica, 35, 944-955. (in Chinese with English abstract) [李 伟, 崔丽娟, 赵欣胜, 张曼胤, 高常军, 张岩, 王义飞 (2015) 太湖岸带湿地土壤动物群落结构与多样性. 生态 学报, 35, 944-955.]

Liao CH, Li JX, Huang HT (1997) Soil animal community diversity in the forest of the southern subtropical region, China. Acta Ecologica Sinica, 17, 549-555. (in Chinese with English abstract) [廖崇惠, 李健雄, 黄海涛 (1997) 南亚 热带森林土壤动物群落多样性研究. 生态学报, 17 , 549-555.]

Lin YH, Zhang FD, Zhang JQ, Ouyang XJ, Mo DS, Zhou GY (2005) Preliminary investigation on temporal and spatial variation of structure of soil fauna community in different natural vegetations of Dinghushan. Acta Ecologica Sinica, 25, 2616-2622. (in Chinese with English abstract) [林英华, 张夫道, 张俊清, 欧阳学军, 莫定生, 周国逸 (2005) 鼎 湖山不同自然植被土壤动物群落结构时空变化. 生态学 报, 25, 2616-2622.]

Liu Y, Zhang A, Yan Y, Li K, Fang Y (2011) Diversity of soil animal community under different land-use types in Chongming Island. Journal of Fudan University (Natural Science), 50, 288-295. (in Chinese with English abstract) [刘扬, 张岸, 严荣, 李恺, 方燕 (2011) 崇明岛不同土地 利用类型下土壤动物群落多样性研究. 复旦学报(自然科 学版), 50, 288-295.]

Malmström A, Persson T, Ahlström K (2008) Effects of fire intensity on survival and recovery of soil microarthropods after a clearcut burning. Canadian Journal of Forest Research, 38, 2465-2475.

Sadaka N, Ponge JF (2003) Soil animal communities in holm oak forests: influence of horizon, altitude and year. European Journal of Soil Biology, 39, 197-207.

Sterzynska M, Bloger T (2004) Collembola of North Bull Island-new records for the Irish coast. Fragmenta Faunistica, 47, 47-50.

Su YC, Gou YB, Yu D, Wang JY (2004) Diversity of soil invertebrate communities at Yushan Hill, Changshu, Jiangsu Province. Biodiversity Science, 12, 333-338. (in Chinese with English abstract) [苏永春, 勾影波, 郁达, 王继元 (2004) 江苏常熟虞山土壤动物群落多样性研究. 生物多 样性, 12, 333-338.]

Sun RY (2001) Principles of Animal Ecology, 3rd version. 
Beijing Normal University Press, Beijing. (in Chinese) [孙 儒泳 (2001) 动物生态学原理, 第3版. 北京师范大学出 版社, 北京.]

Wang Q, Luo Y, Jin YL, You WH (2012) Community structure of soil fauna in forest belt of different areas of Shanghai in Fall. Journal of Ecology and Rural Environment, 28, 669-674. (in Chinese with English abstract) [王强, 罗燕, 靳亚丽, 由文辉 (2012) 上海市外环林带秋季不同区域 土壤动物群落结构. 生态与农村环境学报, 28, 669-674.]

Wardle DA, Bardtett RD, Klironomos JN, Setala H, Putten WH, Wall DH (2004) Ecological linkages between aboveground and belowground biota. Science, 304, 1629-1633.

Wolters V (2001) Biodiversity of soil animals and its function. European Journal of Soil Biology, 37, 221-227.

Wu HT, Lü XG, Yang Q, Jiang M (2006) Ecological characteristics and functions of soil fauna community. Acta Pedologica Sinica, 43, 314-323. (in Chinese with English abstract) [武海涛, 吕宪国, 杨青, 姜明 (2006) 土壤动物主 要生态特征与生态功能研究进展. 土壤学报, 43, 314323.]

Yang YC, Da LJ, Qin XK (2002) A study on the flora of Dajinshan Island in Shanghai, China. Journal of Wuhan Botanical Research, 20, 433-437. (in Chinese with English ab- stract) [杨永川, 达良俊, 秦祥勍 (2002) 上海大金山岛种 子植物区系的研究. 武汉植物学研究, 20, 433-437.]

Yi L (2005) Influences of Secondary Succession of the Damaged Evergreen Broad-leaved Forest on Soil Animal Community in Tiantong, Zhejiang Province. PhD dissertation, East China Normal University, Shanghai. (in Chinese with English abstract) [易兰 (2005) 浙江天童受损常绿阔叶林 的次生演替对土壤动物群落的影响. 博士学位论文, 华 东师范大学, 上海.]

Yi L, You WH, Song YC (2005) Soil animal communities in the litter of the evergreen broad-leaved forest at five succession stages in Tiantong. Acta Ecologica Sinica, 25, 466-473. (in Chinese with English abstract) [易兰, 由文辉, 宋永昌 (2005) 天童常绿阔叶林五个演替阶段调落物中的土壤动 物群落. 生态学报, 25, 466-473.]

Yin WY (1998) Pictorial Keys to Soil Animals of China. Science Press, Beijing. (in Chinese) [尹文英 (1998) 中国土壤 动物检索图鉴. 科学出版社, 北京.]

Yin WY (1992) Subtropical Soil Animals of China. Science Press, Beijing. (in Chinese) [尹文英 (1992) 中国亚热带土 壤动物. 科学出版社, 北京.]

(责任编委: 吴东辉 责任编辑: 间文杰) 